\title{
KINETICS AND MECHANISM OF THE ANODIC DISSOLUTION OF NICKEL IN HCl-DIMETHYLSULPHOXIDE SOLUTIONS
}

\author{
A. B. Delgado, D. Posadas and A. J. Arvla \\ Instituto de Investigaciones Fisicoquimicas Teóricas y Aplicadas, División Electroquímica, \\ Facultad de Ciencias Exactas, Universidad Nacional de La Plata, La Plata, Argentina
}

(Received 28 March 1974; in final form 27 July 1974)

\begin{abstract}
The anodic dissolution of nickel in $\mathrm{HCl}-\mathrm{DMSO}$ solutions containing different supporting electrolytes has been sludien between $20-45^{\circ} \mathrm{C}$. The electiodissolution and electrodeposition are predominantly activated electrode processes. At high anodic potentials and in the presence of perchlorate ions at high concentration passivation sets in.

A probable reaction pathway is postulated which explains most of the experimental findings. Passivation corresponds to a salt precipitation-dissolution process at the electrode vicinity.
\end{abstract}

\section{INTRODUCTION}

Complete quantitative data on metal dissolution processes in non-aqueous electrolytic solutions is rather scarce, since they only exist for iron in $\mathrm{HCl}-$ dimethylsulphoxide (DMSO) solutions [1,2], and for iron in $\mathrm{HCl}$ and $\mathrm{HBr}$ solutions in acetonitrile (ACN)[3]. These are probably the more extended studies on the subject although the information they provide is still very limited as compared to the number of reports, for instance, on the iron group metals in aqucous solutions. Iron anodes in non-aqueous media dissolve and passivate, the corresponding electrode reactions involving the participation of the solvent. This result encourages the systematic investigation of corrosion and passivity processes of other metals of the iron group, in order to evaluate the corresponding kinetic parameters and to interpret them in terms of a reaction mechanism. It is interesting to determine for a particular ionic system in non aqueous media whether a common formal reaction pathway is valid for the iron group metals as it apparently occurs in aqueous solutions $[4,5]$.

\section{EXPERIMFNTAL}

The electrolysis cell as well as solvent and solution preparations are essentially the same as those already described in previous publications $[2,6]$. The working electrodes consisted either of a nickel rotating disc (2.8 $\mathrm{mm}$ dia) or a surface resulting from a nickel rod $\left(2.8 \mathrm{~mm}\right.$ dia) coaxially mounted on a Teflon ${ }^{2}$ rod $\left(1.5 \mathrm{~cm}\right.$ dia) cut at $45^{\circ}$. Flat plate nickel electrodes were used for the X-ray analysis. Nickel (Johnson, Matthey), impurities in ppm: C: 0.02: $\mathrm{Fe} \simeq \mathrm{Mn} \simeq \mathrm{Cu} \simeq \mathrm{Cr} \simeq \mathrm{S} \simeq \mathrm{Si} \simeq 0.005: \mathrm{Ti}: 0.03$ and Co: 0.003 , was used. The electrodes were firstly mechanically polished and then electropolished following the indications given in the literature[7]. The working electrode potential, was referred to a Radiometer type K401 reference electrode, which was mounted through an intermediate $\mathrm{HCl}-\mathrm{NaClO}_{4-}^{-}$ DMSO bridge. The counterelectrode consisted of a bright platinum sheet of $c a 2 \cdot 4 \mathrm{~cm}^{2}$.
DMSO (Baker), $\mathrm{KClO}_{4}$ (Mallinckrodt) $\mathrm{LiClO}_{4}$ $(\mathrm{BDH}),\left[\left(\mathrm{C}_{2} \mathrm{H}_{5}\right)_{4} \mathrm{~N}\right] \mathrm{ClO}_{4}$ (Eastman), $\mathrm{LiCl}$ (Merck Darmstadt), $\mathrm{H}_{2} \mathrm{SO}_{4}$ and $\mathrm{HCl}$ (C. Erba) and $\mathrm{NiCl}_{2} \cdot 6 \mathrm{H}_{2} \mathrm{O}(\mathrm{C}$. Erba) were the starting chemicals used for the solution preparation after purification and drying by conventional methods. $\mathrm{NiCl}_{2} \cdot 6 \mathrm{H}_{2} \mathrm{O}$ was dehydrated under vacuo at $120^{\circ} \mathrm{C}$. Either purified hydrogen or nitrogen were employed both during the solution preparation and the electrochemical runs.

Expcriments wore made between $20-45^{\circ} \mathrm{C}$ with solutions of the following compositions: (i) (0.001-0.025 $0.125) \mathrm{M} \mathrm{HCl}+1 \mathrm{M} \mathrm{KClO}_{4}$; (ii) (0.005-0.03-0.10) M $\mathrm{HCl}+1 \mathrm{M} \mathrm{LiClO}_{4}+0 \cdot 1 \mathrm{M} \mathrm{Cl}^{-}$(at a constant $\mathrm{Cl}^{-}$ ion concentration by additions of $\mathrm{LiCl}$ ); (iii) $0.944 \mathrm{M} \mathrm{HCl}$; (iv) $0.005 \mathrm{M} \mathrm{HCl}+(0.005-0.025-$ $0.1) \mathrm{M} \mathrm{Cl}^{-}+1 \mathrm{M} \mathrm{LiClO}_{4} ;$ (v) $0.005 \mathrm{M} \mathrm{HCl}+(0.001-$ $0.02 \mathrm{M}) \mathrm{NiCl}_{2}+0.052 \mathrm{M} \mathrm{Cl}^{-}+1 \mathrm{M} \mathrm{LiClO}_{4}$; (vi) $\left.0.005 \mathrm{M} \mathrm{HCl}+1 \mathrm{M}\left[\left(\mathrm{C}_{2} \mathrm{H}_{5}\right)_{4} \mathrm{~N}\right)\right] \mathrm{ClO}_{4}$; (vii) $0.005 \mathrm{M}$ $\left.\mathrm{HCl}+0.02 \mathrm{M} \mathrm{NiCl}+1 \mathrm{M}\left[\left(\mathrm{C}_{2} \mathrm{H}_{5}\right)_{4} \mathrm{~N}\right)\right] \mathrm{ClO}_{4}$.

Circuitry employed for coulometry, potentiostatic and galvanostatic experiments and potential sweep techniques is described elsewhere[1,8].

\section{RESULTS}

\section{Current efficiency}

Since the $E / I$ curve exhibited at low potentials an active dissolution and at high potentials a passivity effect, the current efficiency for the metal dissolution was determined in both regions. For a $0.125 \mathrm{M} \mathrm{HCl}$ $\left(1 \mathrm{M} \mathrm{KClO}_{4}\right)$ solution, at $25^{\circ} \mathrm{C}$, the current efficiency in both regions was determined with a nickel disc electrode at $1400 \mathrm{rpm}$. The current efficiency calculated through the increase of $\mathrm{Ni}$ (II) ion concentration in solution on the basis of reaction:

$$
\mathrm{Ni}=\mathrm{Ni}^{2+}+2 e
$$

was $100 \pm 2$ per cent.

$X$-ray diffractograms of nickel samples electrolysed at $0.3 \mathrm{~V}$ for a long period shows only the characteristics of the metal and vestiges of $\mathrm{KClO}_{4}$. 


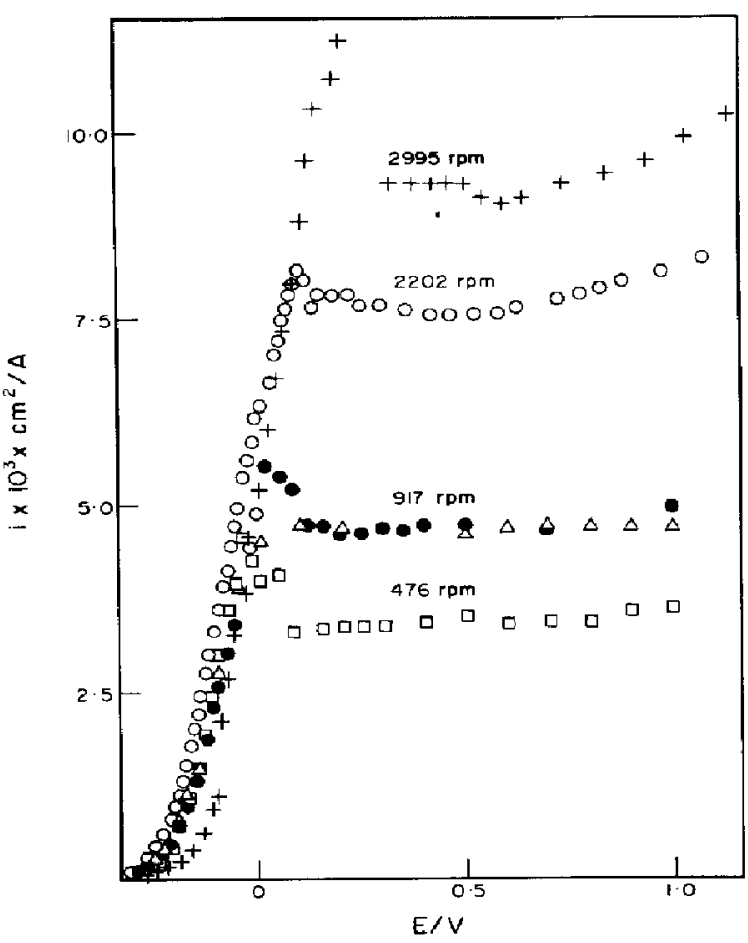

Fig. 1. Stationary potentiostatic $E / i$ cur ves obtained with the rde; $0.125 \mathrm{M} \mathrm{HCl}-1 \mathrm{M} \mathrm{KClO}_{4} ; 25^{\circ} \mathrm{C}$. (D) $476 \mathrm{rpm}$; (๑) $917 \mathrm{rpm}$; ( $\Delta$ ) $917 \mathrm{rpm}$ (run from anodic to cathodic potentials); (o) $2202 \mathrm{rpm}$; (+) $2995 \mathrm{rpm}$.

\section{The rest potentials}

When the metal is in contact with the HCl-DMSO solution it attains a stable rest potential, $E_{r}$, which only depends on the $\mathrm{HCl}$ concentration according to the following equation already given[9]. At $25^{\circ} \mathrm{C}$,

$$
E_{r}(\text { sce })(\text { in V })=(-0.298 \pm 0.020)-0.0592 \log C_{\mathbf{H}^{+}}
$$

Neither $\mathrm{Cl}^{-}$ion concentration nor $\mathrm{Ni}(\mathrm{II})$ ion concentration have any appreciable influence on the rest potential.

\section{Potentiostatic E/I curves}

These curves were run with both fixed and rotating disc nickel electrodes. Those obtained with the latter were very reproducible and will be described more extensively. Potentiostatic E/I curves (476-2995 rpm) exhibit the following characteristics (Fig. 1). At a fixed rotation speed, $\omega$, the region from the rest potential up to $-0.1 \mathrm{~V}$ (region I), the current increases with the applied potential and it is practically unaffected by stirring conditions. From $-0 \cdot 1 \mathrm{~V}$ upwards the current increases attaining a maximum (region $I$ ), and finally, at about $0.1 \mathrm{~V}$ the current decreases with the potential attaining a limiting value at higher potentials (region III). The current around the maximum increases with $\omega$.

The E/I curve (region I) approaches a Tafel line between -0.35 and $-0.20 \mathrm{~V}$ with a slope comprised between 80 and $90 \mathrm{mV}$ (Fig. 2). The limiting current (region III) increases linearly with the $\omega^{1 / 2}$. The occurrence of both the passivating effect and the limiting

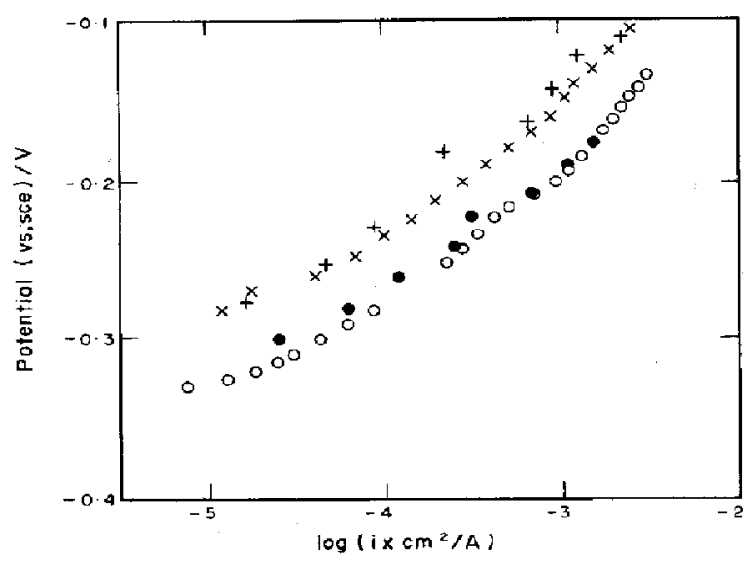

Fig. 2. Tafel plots at different $\mathrm{HCl}$ concentrations and at 476 rpm. $(x,+)$ 0.025 M HCl-1 M KClO $;$; $(O$, $0.125 \mathrm{M} \mathrm{HCl}-1 \mathrm{M} \mathrm{KClO}_{4} .25^{\circ} \mathrm{C}$.

current regions depends on the presence of $\mathrm{ClO}_{4}^{-}$ions in the solution. Thus, if a $0-944 \mathrm{M} \mathrm{HCl}$ solution is electrolysed at $25^{\circ} \mathrm{C}$ under potentiostatic conditions up to $1 \cdot 0 \mathrm{~V}$, a steady current is established, without any appreciable passivation. Under these circumstances neither current maxima nor anodic limiting current are observed. This behaviour is reversed when a $0.125 \mathrm{M} \mathrm{HCl}\left(1 \mathrm{M} \mathrm{KClO}_{4}\right.$ ) solution is used (Fig. 3).

$E / I$ curves recorded from $1.0 \mathrm{~V}$ downwardly coincide with those recorded from the rest potential upwardly both in regions I and III, although the anodic current maxima is no longer observed. Otherwise the current at the maximum, under potentiostatic conditions, attains a steady value after about 60 minutes.

The anodic current is independent of Ni(II) ion concentration and apparently it increases lincarly with the square root of the $\mathrm{H}^{+}$ion concentration. Water (up to $10,000 \mathrm{ppm}$ ) has no appreciable influence on the dissolution process (Fig. 4).

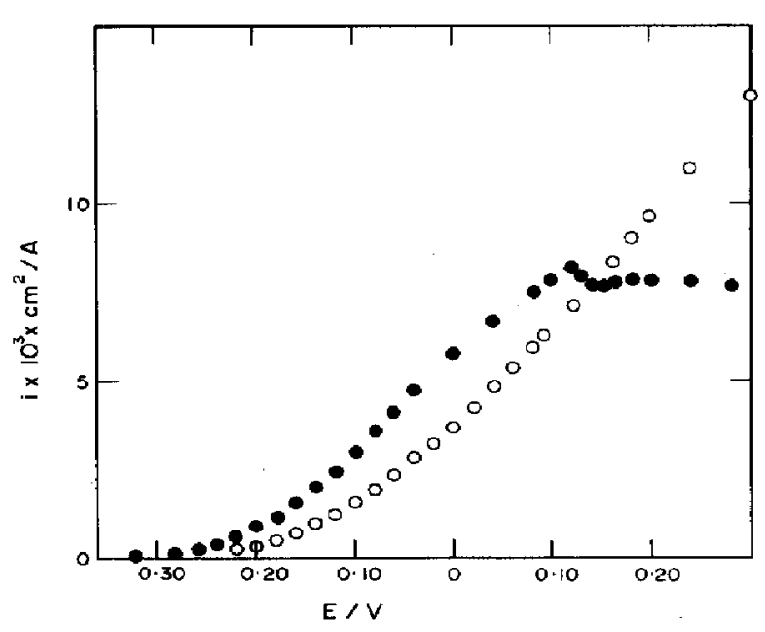

Fig. 3. Potentiostatic stationary $E / i$ curves run with a rde; $0.944 \mathrm{M} \mathrm{HCl}(0) ; 0.125 \mathrm{M}$ HCl-1 M KClO $1739 \mathrm{rpm} ; 25^{\circ} \mathrm{C}$. 


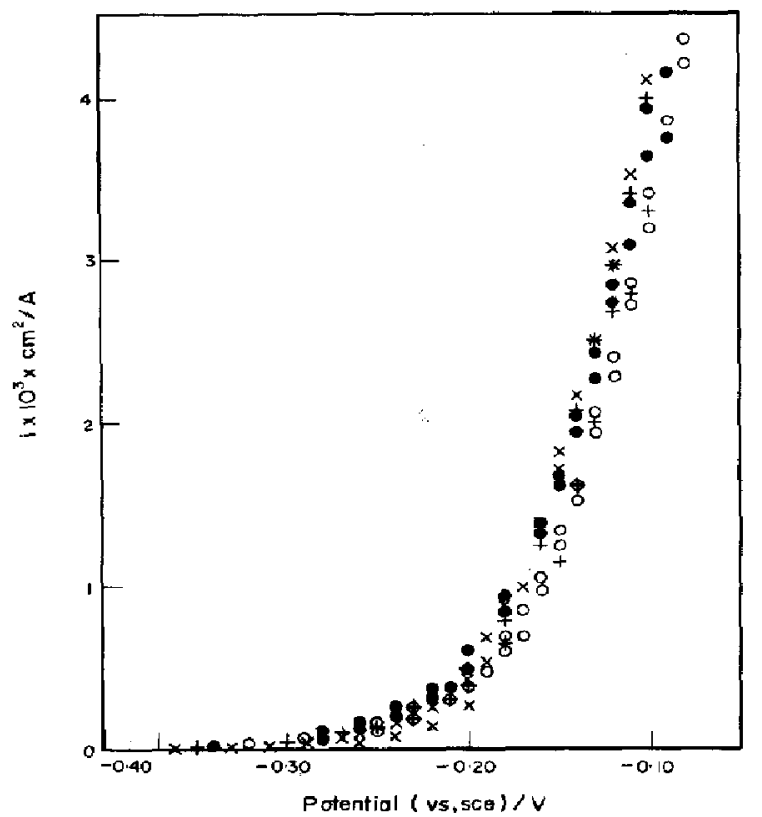

Fig. 4. Potentiostatic stationary $E / i$ curves; $0-005 \mathrm{M} \mathrm{HCl}-$ $1 \mathrm{M} \mathrm{KClO}_{4} ;(0) 0.04 \% \mathrm{H}_{2} \mathrm{O}$; (+) $0.10 \% \mathrm{H}_{2} \mathrm{O} ;(x) 0.30 \%$ $\mathrm{H}_{2} \mathrm{O}$; (O) $1 \% \mathrm{H}_{2} \mathrm{O} ; 30^{\circ} \mathrm{C}$.

\section{Potentiodynamic E/I curves}

Potentiodynamic $E / I$ curves were obtained with a disc electrode under rotation. Figure 5 shows semilogarithmic plots of potentiodynamic curves after correction for the pseudo-ohmic drop. The linear Tafel plots cover approximately two logarithmic decades of cur-

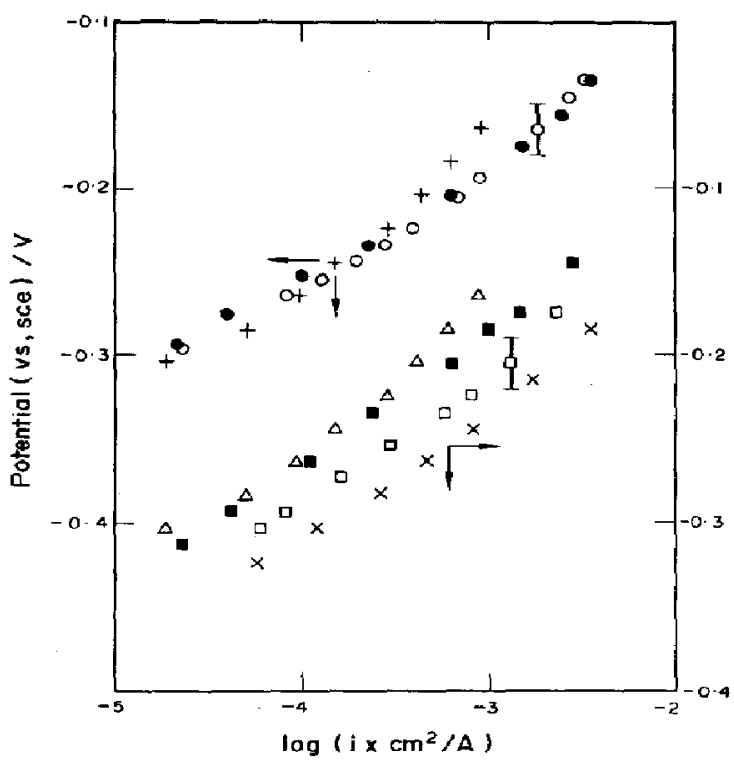

Fig. 5. Semilogarithmic plots of potentiodynamic curves;

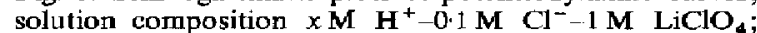

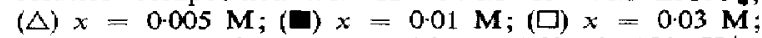
(x) $x=0.1 \mathrm{M}$. Solution composition $y \mathrm{M} \mathrm{Cl}^{-}-0.005 \mathrm{M} \mathrm{H}^{+}$ $1 \mathrm{M} \mathrm{LiClO}_{4}$; (0) $y=0.005 \mathrm{M}$; (0) $0.025 \mathrm{M}$; (+) $0.095 \mathrm{M}$; $25^{\circ} \mathrm{C} .10 \mathrm{mV} / \mathrm{s}$ and $1738 \mathrm{rpm}$.

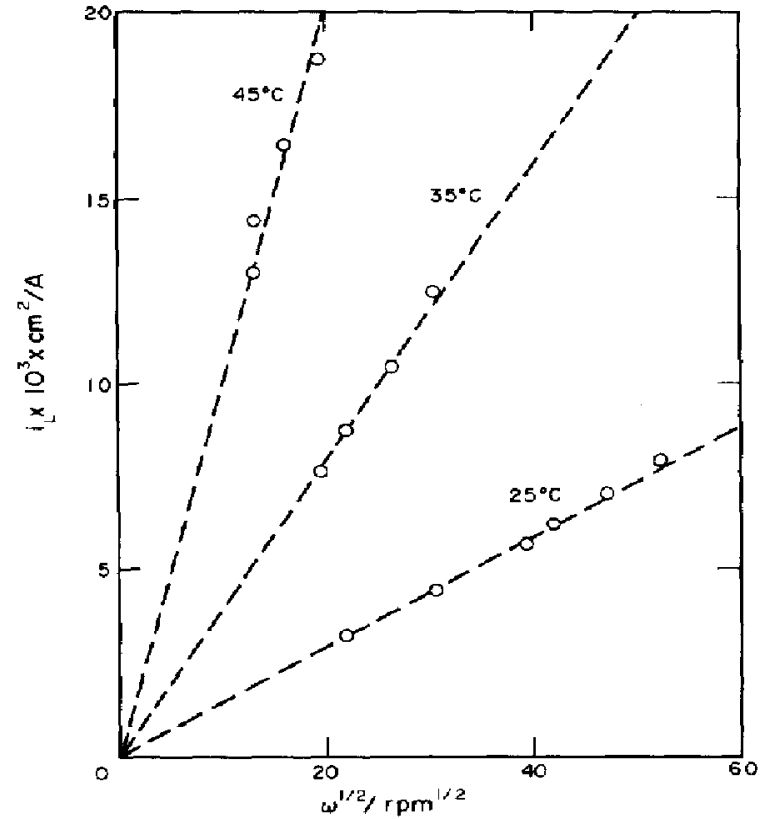

Fig. 6. $i_{L}$ vs $\dot{\omega}^{1 / 2}$ plot; $0.005 \mathrm{M} \mathrm{HCl}-1 \mathrm{M} \mathrm{KClO}_{4} ; 25^{\circ} \mathrm{C}$.

rent with slopes ranging from 70 to $90 \mathrm{mV}$, at $25^{\circ} \mathrm{C}$. At a constant potential the current increases slightly on increasing the $\mathrm{H}^{+}$ion concentration, the probably reaction order is no greater than $0-5$.

\section{The anodic limiting current}

Region III was studied with the rde under different experimental conditions. At $0.3 \mathrm{~V}$, the anodic limiting current increases linearly with $\omega^{1 / 2}$ (Fig. 6) and the corresponding straight lines, at any temperature, intercept the origin of coordinates. The limiting current at a constant rotation speed increases with temperature fitting an Arrhenius plot (Fig. 7), with an apparent activation energy equal to $17.8 \pm 1.0 \mathrm{Kcal} / \mathrm{mole}$. This value exceeds the predictions of any simple mass transport process. The height of the limiting current plateau decreases with the concentration of Ni(II) (Fig. 8), and a reverse effect is produced on increasing the $\mathrm{Cl}^{-}$ion concentration. Neither the $\mathrm{H}^{+}$ion concentration nor the addition of water up to $2000 \mathrm{ppm}$ shows any definite effect in this region of the $E / I$ curve.

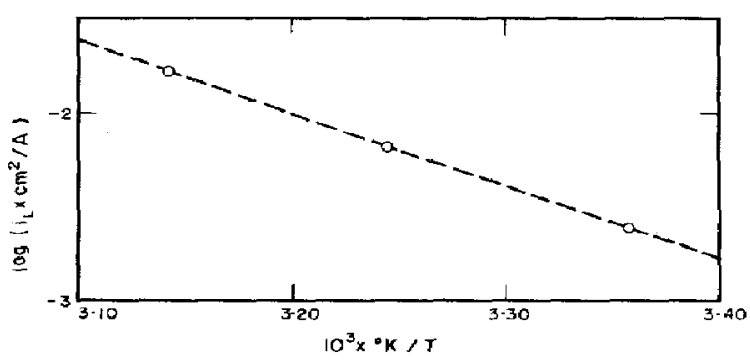

Fig. 7. Arrhenius plot of the limiting current; 0-005 $\mathbf{M}$ $\mathrm{HCl}-1 \mathrm{M} \mathrm{KClO}_{4} ; 275 \mathrm{rpm}$. 


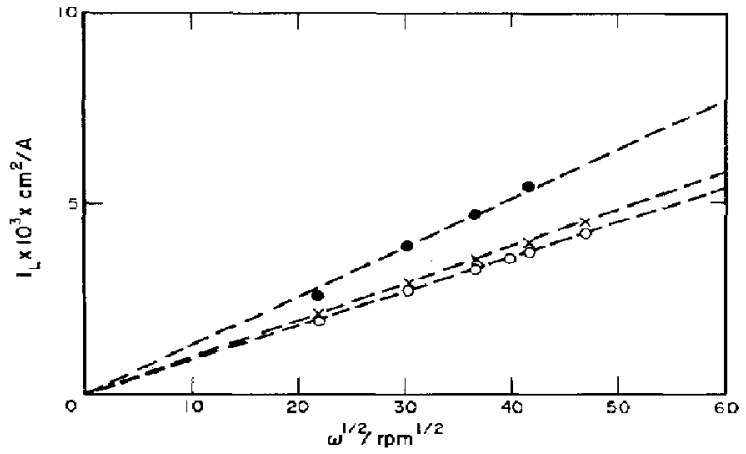

Fig. 8. Effect of Ni(II) on the limiting current; (O) $0-01 \mathbf{M}$ HCl-0.09 M LiCl-1 $\mathrm{M} \mathrm{LiClO}_{4} ;(\times)$ 0.01 M HCl-0.09 M $\mathrm{LiCl}-0.01 \mathrm{M} \mathrm{NiCl}-1 \mathrm{M} \mathrm{LiClO}_{4} ;$ (O) $0.005 \mathrm{M} \mathrm{HCl}-$ $0.007 \mathrm{M} \mathrm{LiCl}-0.02 \mathrm{M} \mathrm{NiCl}_{2}-1 \mathrm{M} \mathrm{LiClO}_{4} .25^{\circ} \mathrm{C}$

\section{Electrode differential capacitance}

The electrode differential capacitances were evaluated from the potential decay curves at current interruption both for the anodic and cathodic processes. In the $0.058-0.243 \mathrm{~V}$ overpotential range (referred to $E_{\mathbf{r}}$ ), the apparent differential capacitance is between 20 and $36 \mu F / \mathrm{cm}^{2}$. In the range -0.8 to $-1.2 \mathrm{~V}$ its value is about $30 \mu F / \mathrm{cm}^{2}$.

\section{Potentiostatic pulses}

The current-time profiles (Fig. 9) recorded with various electrolytic solutions in the overpotential range $0.65-1.55 \mathrm{~V}$ exhibit a rapid increase of current up to a maximum value, afterwards decreasing to a very small steady value at $t_{f}$. The charge involved at the onset of passivation, detcrmincd after integration of the $I / t$ record, diminishes linearly with the magnitude of the applied potential pulse. The charge, $Q$, related to the passivation effect corresponds to a thick layer of an insoluble species, such as precipitated $\mathrm{Ni}\left(\mathrm{CO}_{4}\right)_{2}$.

The charge obtained from the potentiostatic pulses is in close agreement with that evaluated from other techniques, as described further on. A linear $Q$ vs $t_{f}^{1 / 2}$ dependence is found, although the corresponding straight line does not go through the origin of coordinates. The latter suggests that a constant charge is required before passivation sets in (Fig. 10).

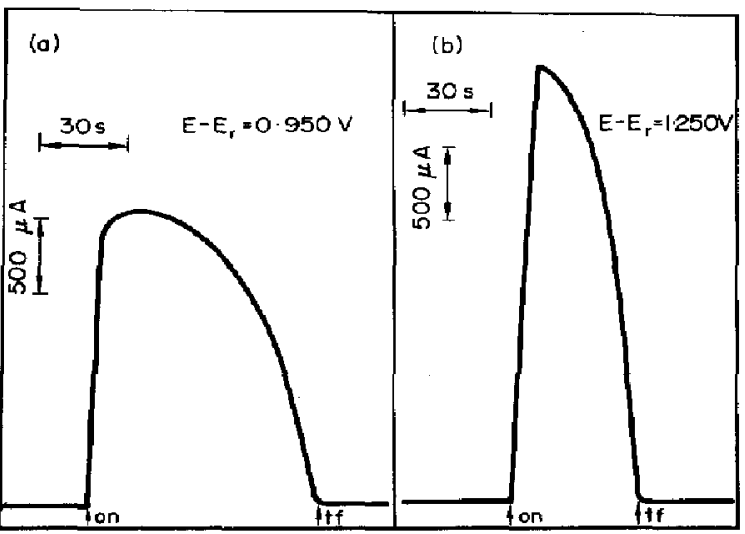

Fig. 9. Potentiostatic current/time curves; $0.025 \mathrm{M} \mathrm{HCl}$ $1 \mathrm{M} \mathrm{KClO}_{4}: 25^{\circ} \mathrm{C}$

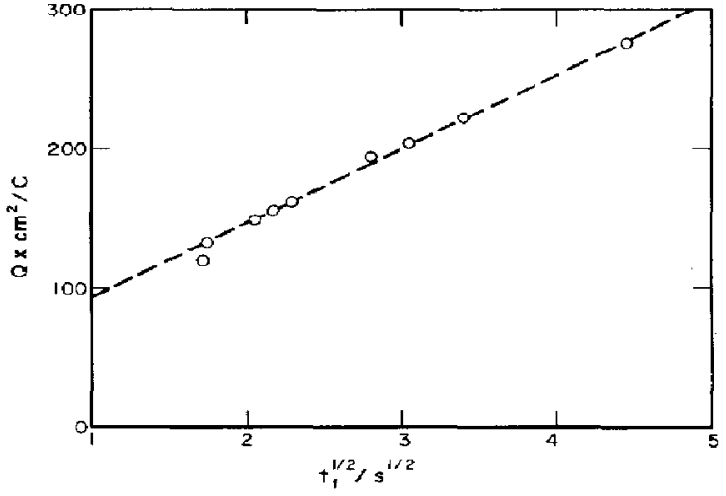

Fig, 10. $Q$ os $t_{f}^{1 / 2}$ plot; $0025 \mathrm{M} \mathrm{HCl}^{1} \mathrm{M} \mathrm{KClO}_{4} ; 25^{\circ} \mathrm{C}$

\section{Transition times}

Galvanostatic transition times were measured in the range from 0.72 to $19.6 \mathrm{~mA}$ using still electrolytic solutions. The error of the galvanostatic pulse up to $11.0 \mathrm{~mA}$ was less than 2 per cent. Potential/time displays (Fig. 11) exhibit an initial abrupt potential jump, then a region of nearly steady potential and finally a sudden potential increase after a transition time $t$. For $\tau<10 \mathrm{~s}$ the product $i \tau^{1 / 2}$ is reasonably constant (Table 1), while at $\tau>10 \mathrm{~s}$ it slightly but steadily decreases (Fig. 12). No simple theoretical relationship is adequate to fit the galvanostatic $E / t$ curves.

\section{Potentiodynamic E/I curves}

These runs were made with different solutions either still or stirred at potential sweep rates, $v$, between 5 and $150 \mathrm{mV} / \mathrm{s}$, with automatic compensation of the olwic drop (Fig. 13). The initial part of the voltammograms is independent of both stirring and $v$. The voltammograms exhibit an anodic current peak whose height and peak potential increase when $v$ increases. The irreproducibility, however, turns it difficult to establish a reliable quantitative law for both dependences. The charge required for passivation to set in, increases also with $v$. Furthermore, the charge required for passivation is larger when the solution is stirred (Table 2).

The voltammograms are more asymmetric in shape as either $v$ or $\omega$ increase, resembling those of activated processes involving an appreciable ohmic contribution due to the formation of the insoluble passivating salt

Table 1. Data obtained from galvanostatic transients. $0.125 \mathrm{M} \mathrm{HCl}-1 \mathrm{M} \mathrm{KClO}_{4} .25^{\circ} \mathrm{C}$.

\begin{tabular}{ccl}
\hline $\begin{array}{c}i \times 10^{3} \\
\left(\mathrm{~A} / \mathrm{cm}^{2}\right)\end{array}$ & $\begin{array}{c}\left(i \tau^{1 / 2}\right) \times 10^{3} \\
\left(\mathrm{~A} . \mathrm{s}^{\mathrm{L} / 2}\right)\end{array}$ & $\begin{array}{l}Q \times 10^{3} \\
\left(\mathrm{C} / \mathrm{cm}^{2}\right)\end{array}$ \\
\hline 8.19 & $83.3 \pm 0.3$ & $846 \pm 100$ \\
18.4 & $94.3 \pm 0.5$ & $484 \pm 60$ \\
19.3 & $87.0 \pm 0.6$ & $414 \pm 30$ \\
39.8 & $129 \pm 0.1$ & $416 \pm 10$ \\
80.8 & $164 \pm 0.3$ & $333 \pm 20$ \\
83.1 & $166 \pm 0.5$ & $334 \pm 30$ \\
88.7 & $171 \pm 0.2$ & $324 \pm 15$ \\
130 & $172 \pm 0.7$ & $227 \pm 15$ \\
154 & $180 \pm 0.3$ & $203 \pm 30$ \\
193 & $180 \pm 0.6$ & $128 \pm 30$ \\
223 & $150 \pm 0.6$ & $103 \pm 10$ \\
\hline
\end{tabular}




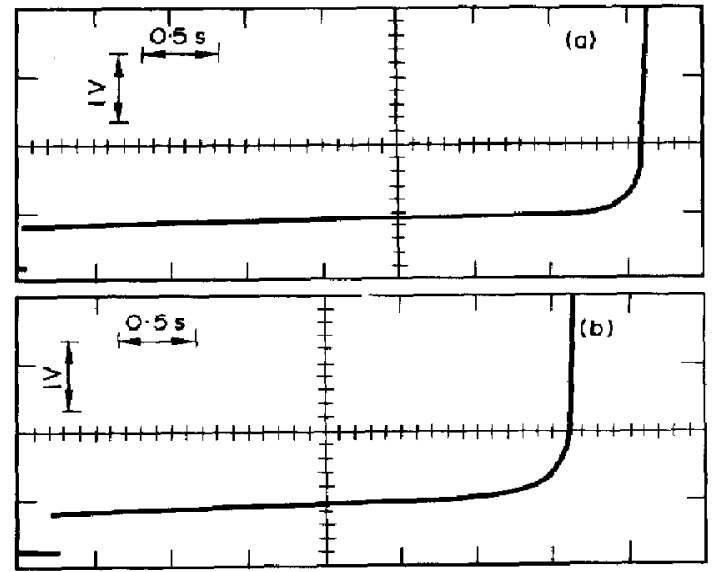

Fig. 11. Galvanostatic potential/time curves; (a) $7-3 \times 10^{-3}$ A; (b) $8.4 \times 10^{-3} \mathrm{~A} ; 0.125 \mathrm{M} \mathrm{HCl} 1 \mathrm{M} \mathrm{KClO} ; 25^{\circ} \mathrm{C}$; Electrode area $8.79 \times 10^{-2} \mathrm{~cm}^{2}$.

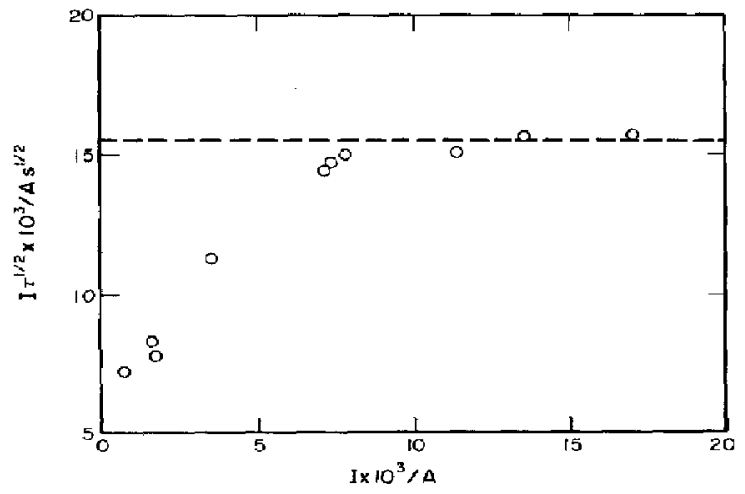

Fig. 12. I $\tau^{1 / 2}$ us I plot; $0.125 \mathrm{M} \mathrm{HCl}-1 \mathrm{M} \mathrm{KClO}_{4}$ $25^{\circ} \mathrm{C}$; Electrode area $8.79 \times 10^{-2} \mathrm{~cm}^{2}$.

layer already mentioned at the electrode surface. Otherwise, the voltammograms run at low $v$ can be reasonably fitted to the equation of an activated electrode process under diffiusion control. (Fig. 13)[10].

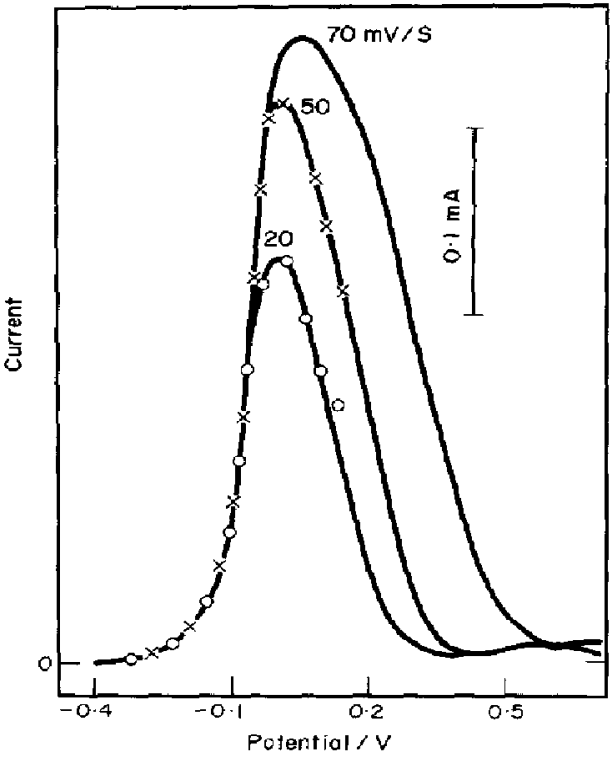

Fig. 13. Potential sweep voltammetry; $0.005 \mathrm{M} \mathrm{HCl}$ $1 \mathrm{M} \mathrm{LiClO}_{4} ; 25^{\circ} \mathrm{C}$. $O$ and $\times$ are data calculated with the equation of an irreversible diffusion controlled process[10].

\section{The cathodic $E / I$ curves}

Reproducible cathodic $E / I$ curves were obtained with potentiodynamic sweeps of 1 and $10 \mathrm{mV} / \mathrm{s}$, using solutions containing $0.02 \mathrm{M} \mathrm{NiCl}_{2}, 0.005 \mathrm{M} \mathrm{HCl}$ and $1 \mathrm{M}\left[\left(\mathrm{C}_{2} \mathrm{H}_{5}\right)_{4} \mathrm{~N}\right] \mathrm{ClO}$. The $E / I$ curves obtained either with still or stirred solutions (Fig. 14) show the $\mathrm{H}^{+}$ion discharge current[9] from the rest potential down to $-0.8 \mathrm{~V}$ (portion $\mathrm{I}$ ). At potential more cathodic than $-0.8 \mathrm{~V}$ the electroreduction of $\mathrm{Ni}$ (II) is observed (portions II and III). The latter process exhibits a cathodic prewave (portion II). Beyond $-1.8 \mathrm{~V}$ the simultaneous electroreduction of the solvent takes place. The $E / I$ curve related to $\mathrm{Ni}(\mathrm{II})$ reduction fits at potentials more anodic than $-1.4 \mathrm{~V}$ a semilogarithmic plot (Fig. 15) involving a cathodic Tafel slope approaching the ratio $2 \cdot 3(2 R T / F)$.

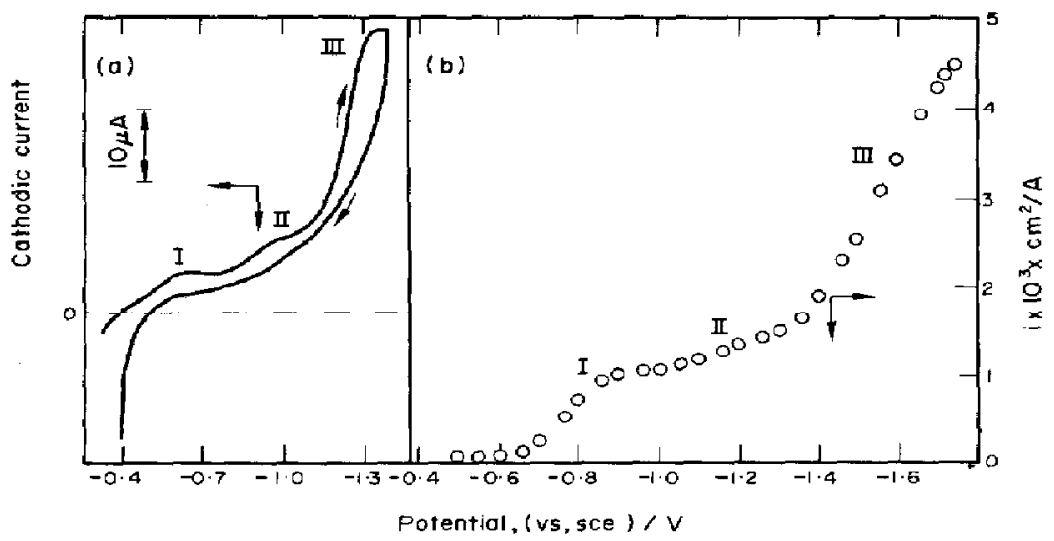

Fig. 14. Cathodic $E / i$ curves run at $10 \mathrm{mV} / \mathrm{s} ; 0.005 \mathrm{M} \mathrm{HCl}-0-020 \mathrm{M} \mathrm{NiCl}_{2}-1 \mathrm{M}\left[\left(\mathrm{C}_{2} \mathrm{H}_{5}\right)_{4} \mathrm{~N} \mathrm{ClO}_{4}\right.$

$30^{\circ} \mathrm{C}$. (a) still solution; (b) $2202 \mathrm{rpm}$. 
Table 2. Charge required for passivity obtained from potentiodynamic runs. $0.005 \mathrm{M} \mathrm{HCl}-1 \mathrm{M} \mathrm{KClO} \mathrm{K}_{4} .25^{\circ} \mathrm{C}$

\begin{tabular}{cc}
$\begin{array}{c}v \\
(\mathrm{mV} / \mathrm{s})\end{array}$ & $\begin{array}{c}Q \times 10^{3} \\
\left(\mathrm{C} / \mathrm{cm}^{2}\right)\end{array}$ \\
10 & Still solution \\
20 & 294 \\
30 & 397 \\
40 & 350 \\
50 & 351 \\
60 & 278 \\
70 & 304 \\
80 & 289 \\
Stirred solution $(417 \mathrm{rev} / \mathrm{min})$ \\
5 & 188 \\
8 & 1146 \\
8 & 1197 \\
10 & 1334 \\
\hline
\end{tabular}

\section{DISCUSSION}

Results indicate that the electrochemical behaviour of polycrystalline $\mathrm{Ni}$ in $\mathrm{HCl}-\mathrm{DMSO}$ solutions with different supporting electrolytes, exhibits an active dissolution region and a passivation region, the latter being apparently related to the local precipitation of an insoluble salt. In spite of the complexity of the processes involved their explanation in terms of a single reaction pathway may be attempted.

Possible reaction pathways for the active dissolution process

It is obvious, from the above reported results, that any simple reaction mechanism such as the one postulated for the anodic dissolution of $\mathrm{Ni}$ in concentrated aqueous $\mathrm{NiCl}_{2}$ acid solutions $[11,12]$ without solvent

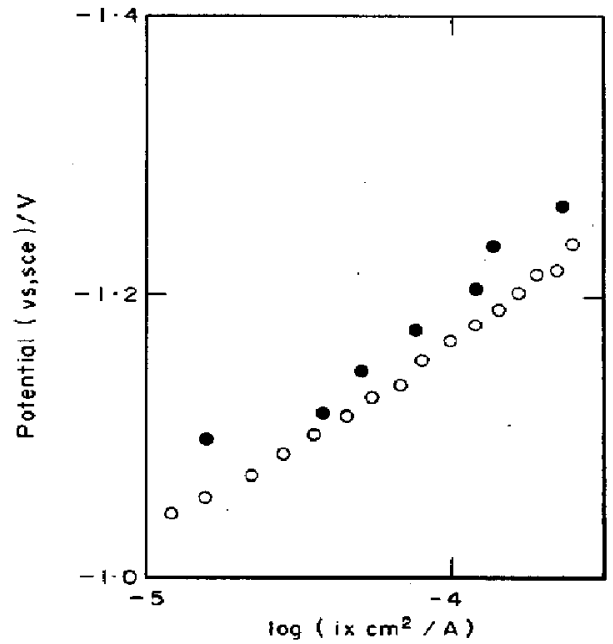

Fig. 15. Tafel plots for the cathodic $E / i$ curves shown in Fig. 14: (O) $\omega=0$. (O) $2202 \mathrm{rpm}$.

Accordingly, two main reaction models can be proposed. Either the molecules or the ions are the predominant species initially adsorbed at the electrode surface.

Mechanism $A$. Let us assume that the solvent adsorbs preferentially to the anions. The fact that the anodic stationary Tafel slope is lower than $2 R T / F$ suggests that it is rather unlikely that the initial electron transfer is rate determining. Furthermore, the values of the apparent electrode capacitance are low and practically potential independent in the region where the reactions were investigated. Consequently, it is reasonable to admit that the degree of surface coverage by any reaction intermediate is negligible. Therefore, the following first reaction scheme can be discussed:

$$
\begin{aligned}
\mathrm{Ni}+\mathrm{DMSO} & =\mathrm{Ni}(\mathrm{DMSO}) \\
\mathrm{Ni}(\mathrm{DMSO})+\mathrm{HCl} & =\mathrm{Ni}\left(\mathrm{Cl}^{-}\right)+\mathrm{H}^{+}+\mathrm{DMSO} \\
\mathrm{Ni}\left(\mathrm{Cl}^{-}\right) & =\mathrm{Ni}(\mathrm{Cl})+e \\
\mathrm{Ni}(\mathrm{Cl}) \stackrel{\text { rds }}{\longrightarrow} & \mathrm{Ni}(\mathrm{Cl})^{+}+e \\
\mathrm{Ni}(\mathrm{Cl})^{+}+5 \mathrm{DMSO}^{+}+3 \mathrm{HCl} & =\mathrm{NiCl}_{4}^{2-}+3 \mathrm{H}^{+}+5 \mathrm{DMSO} \\
\mathrm{NiCl}_{4}^{2-}+x \mathrm{DMSO} & =\left[\mathrm{NiCl}_{y}\left(\mathrm{DMSO}_{x}\right]^{2-}+z \mathrm{Cl}^{-}\right.
\end{aligned}
$$

participation, is inadequate to interpret the reactions of $\mathrm{Ni}$ electrodes in $\mathrm{HCl}-\mathrm{DMSO}$ solutions.

Consecutive reaction mechanisms involving the participation of the solvent, such as those earlier proposed for the iron group metals either in aqueous or nonaqueous electrolytes must be considered. A review of these mechanisms is given in [5]. Under the present circumstances, taking into account the composition of the metal/electrolyte interface, an interaction between the metal surface and either the solvent molecules or the halide ions must occur. Adsorption of solvent molecules probably occurs preferentially near the potential of zero charge $(p z c)$ while anion adsorption should prevail at the anodic side of the pzc. where $y+z=4 ; 0 \leqslant x \leqslant 6 ; 0 \leqslant y \leqslant 4$.

Let us assume that steps (A-1)-(A-3) are at equilibrium, step $(A-4)$ is the rate determining one and reactions (A-5) and (A-6) are equilibria with the participation of the various complexes of $\mathrm{Ni}$ with $\mathrm{Cl}^{-}$and DMSO[13]. According to mechanism A, the total anodic dissolution reaction of $\mathrm{Ni}$ in $\mathrm{DMSO}-\mathrm{HCl}$ solutions is:

$$
\mathrm{Ni}+4 \mathrm{HCl}=\mathrm{NiCl}_{4}^{2-}+4 \mathrm{H}^{+}+2 e .
$$

If (A-4) is rate determining the anodic $c d, i_{a}$, can be written as follows:

$$
i_{a}=2 F k_{4} \theta_{\mathrm{NiCl}} \exp \left(\alpha_{a, 4} f E\right)
$$


where $\theta_{\mathrm{NiCl}}$ is the degree of surface coverage by the reaction intermediate, $k_{n}$ and $\alpha_{n}$ are respectively the specific rate constant and the transfer coefficient assisting the reaction in the anodic direction of step $n ; f=$ $F / R T$ and $E$ is the electrode potential measured against the sce. Under a quasi-steady state for the preceeding steps, equation (4) results:

$$
i_{a}=k_{4}^{\prime} K_{\mathrm{t}} K_{2} K_{3}\left(C_{\mathrm{HC}}^{\mathrm{a}}\right)\left(C_{\mathrm{H}^{+}}\right)^{-1} \exp (3 / \mathrm{E} / 2)
$$

where

$$
\begin{aligned}
k_{4} & =2 F k_{4}\left(1-\theta_{\mathrm{DMSO}}-\theta_{\mathrm{Ct}^{-}}-\theta_{\mathrm{NiCl}}\right) \\
& -2 F k_{4}\left(1-\theta_{m}\right) \text { and } K_{i}=k_{i} / k_{-i}
\end{aligned}
$$

Equation (5) shows a -1 st order dependence with respect to $\mathrm{H}^{+}$ions and a ist order dependence with respect to $\mathrm{HCl}$. This prediction, however, may be unrealistic since $\mathrm{HCl}$ is strongly ionized in DMSO[14]. Therefore, if $\mathrm{C}_{\mathrm{HCl}}=K_{d}\left(\mathrm{C}_{\mathrm{H}^{+}}\right)\left(\mathrm{C}_{\mathrm{Cl}^{-}}\right)$, equation (5) becomes:

$$
i_{a}=k_{4}^{\prime} K_{1} K_{2} K_{3} K_{d}\left(\mathrm{C}_{\mathrm{Cl}^{-}}^{0}\right) \exp (3 f E / 2) .
$$

This rate equation involves a Tafel slope equal to $2 R T /$ $3 F$ if no diffusion effects interfere. The situation, however, may be rather different if the rate determining step also determines the diffusion rate of species formed at the electrode or participating at the double layer structure. Thus, during the reaction, $\mathrm{H}^{+}$ions are produced at a rate equal to $i_{4}=i_{a}$ at the electrochemical interface, then they diffuse out of the electrode region at the same rate:

$$
i_{a}=-F D_{\mathrm{H}^{+}}\left(\frac{\partial \mathrm{C}_{\mathrm{H}^{+}}}{\partial x}\right)_{x=0}
$$

Equation (10) implies a cathodic Tafel slope equal to $2 R T / F$.

The rate equation for the hydrogen evolution reaction on $\mathrm{Ni}$ in HCl-DMSO is [9]:

$$
i_{c, \mathbf{H}^{+}}=k_{c, \mathbf{H}^{+}}\left(\mathbf{C}_{\mathbf{H}^{+}}^{\infty}\right) \exp (-f E / 2)
$$

The dependences of the corrosion potential, $E_{\text {corr }}$, on $\mathrm{H}^{+}$ion concentration and $\mathrm{Cl}^{-}$ion concentration are obtained from equations (6) and (11). Thus, at low $c d$, $\left(C_{\mathrm{H}^{+}}\right)_{x=0} \approx\left(C_{\mathrm{H}^{+}}\right)_{x \rightarrow \infty}$, when $i_{a}=i_{c, \mathrm{I}^{+}}=i_{\text {curr }} E=$ $E_{\text {corr }}$ and it results:

$E_{\text {corr }}=E_{\text {ciorr }}^{\circ}-(R T / 2 F) \ln \left(\mathrm{C}_{\mathrm{Cl}^{-}}\right)+(R T / 2 F) \ln \left(\mathrm{C}_{\mathrm{H}^{+}}\right)$

and

$$
\frac{\partial E_{\text {corr }}}{\partial \ln \mathrm{C}_{\mathrm{H}^{+}}}=\frac{R T}{2 F} ; \quad \frac{\partial E_{\text {corr }}}{\partial \ln \mathrm{C}_{\mathrm{C}^{-}}}=-\frac{R T}{2 F} .
$$

After introducing $E_{\mathrm{cesr}}$ as given by equation (12) either into equation (6) or equation (11), one obtains:

$$
\begin{gathered}
i_{\text {corr }}=\left(k_{4}^{\prime} K_{1} K_{2} K_{3}\right)\left(\mathrm{C}_{\mathrm{Cl}^{-}}\right)^{1 / 4}\left(\mathrm{C}_{\mathrm{H}^{+}}\right)^{3 / 4} \\
\frac{\partial \ln i_{\text {corr }}}{\partial \ln \mathrm{C}_{\mathrm{H}^{+}}}=\frac{3}{4} ; \quad \frac{\partial \ln i_{\text {corr }}}{\partial \ln \mathrm{C}_{\mathrm{Cl}^{-}}}=\frac{1}{4}
\end{gathered}
$$

The predictions of mechanism $A$ are compared to experimental results in Table 3. A partial correspondence between experimental and theoretical results is achieved.

\section{Mechanism $B$}

In the second reaction scheme one considers the preferential adsorption of chloride ion as earlier postulated for the anodic dissolution of iron in acid medium in the presence of halide ions [15]. Anion adsorption predominates at potentials more positive than the $p z c$. Thus,

$$
\begin{aligned}
\mathrm{Ni}+\mathrm{Cl}^{-} & =\mathrm{Ni}\left(\mathrm{Cl}^{-}\right) \\
\mathrm{Ni}\left(\mathrm{Cl}^{-}\right)+\mathrm{DMSO} & =\mathrm{Ni}(\mathrm{B})^{-}+\mathrm{H}^{+}+\mathrm{Cl}^{-} \\
\mathrm{Ni}(\mathrm{B})^{-} & =\mathrm{Ni}(\mathrm{B})+e \\
\mathrm{Ni}(\mathrm{B}) & \stackrel{\text { rds }}{\longrightarrow}(\mathrm{NiB})^{+}+e \\
(\mathrm{NiB})^{+}+(z+y+1) \mathrm{HCl}+(x-1) \mathrm{DMSO} & =\left[\mathrm{NiCl}_{y}(\mathrm{DMSO})_{x}\right]^{2-y}+\left(z+1 \mathrm{Cl}^{-}\right.
\end{aligned}
$$

An approximate solution of equation $(7)$ is obtained after assuming a linear concentration profile extending from the electrode surface up to $\delta_{N}$, the Nernst diffusion layer. If $\left(\mathrm{C}_{\mathrm{H}^{+}}\right)_{x=0} \gg\left(\mathrm{C}_{\mathrm{H}^{+}}\right)_{x \rightarrow \infty}$ one obtains:

$$
\mathrm{C}_{\mathrm{H}^{+}}^{\mathrm{o}}=\frac{\delta_{N} i_{\mathrm{a}}}{F D_{\mathrm{H}^{+}}}
$$

Hence, equation (5) can be expressed as follows:

$i_{a}=\left(\frac{F D_{\mathrm{H}}+k_{4}^{\prime} K_{1} K_{2} K_{3}}{\delta_{N}}\right)^{1 / 2}\left(\mathrm{C}_{\mathrm{HCl}}\right)^{1 / 2} \exp (3 f E / 4)$

yielding now an anodic Tafel line with a slope equal to $4 R T / 3 F$.

On the basis of the same rate determining step, mechanism A predicts the following current density equation for the cathodic discharge of $\mathrm{Ni}$ (II) species:

$$
i_{\mathrm{c}}=k_{-4}\left(\mathrm{CNC}^{+}\right) \exp (-f E / 2)
$$

The $\left(\mathrm{NiCl}^{+}\right)$concentration is determined by the ionic equilibria involving the different complex ionic species. where $x, y$, and $z$ are the same numbers already defined for Mechanism $\Lambda$ and $B=\mathrm{CH}_{3} \mathrm{SOCH}_{2}^{-}$. If steps $\mathrm{B}-1$ and B-2 were relatively fast processes, the influence of the adsorption process would only appear as a double layer effect in the rate equation. If step (B-4) is rate determining one obtains:

$$
i_{a}=k_{\alpha}^{\prime} K_{1} K_{2} K_{3}\left(C_{\mathrm{H}^{+}}^{a}\right)^{-1} \exp (3 f E / 2)
$$

with

$$
k_{4}^{\prime}=2 F k_{4}\left(1-\theta_{n}\right) C_{\text {DMSO }} .
$$

After correcting for the $\mathrm{H}^{+}$ion diffusion, equation (15) becomes:

$$
i_{a}=\left(\frac{F D_{\mathrm{H}}+k_{4}^{\prime} K_{\mathrm{t}} K_{2} K_{3}}{\delta_{N}}\right)^{1 / 2} \exp (3 f E / 4)
$$

Equations (16) and (18) involve respectively the Tafel slopes $2 R T / 3 F$ and $4 R T / 3 F$ and they can be consi- 
dered as limiting cases of the following cxpression:

$i_{a}=k_{4}^{\prime} K_{1} K_{2} K_{3}\left(\frac{\delta_{N^{*}} i_{a}}{F D_{\mathrm{H}^{+}}}+\mathrm{C}_{\mathrm{H}^{+}}^{\alpha}\right)^{-1} \exp (3 f E / 2)$

The rate equation for the cathodic deposition of Ni(II) obtained from this mechanism is the same as that for mechanism $A$, but the dependences of $E_{\text {carr }}$ and $i_{\text {corr }}$ on the $\mathrm{H}^{+}$ion and $\mathrm{Cl}^{-}$ion concentrations ate different:

$$
\begin{aligned}
& E_{\text {corr }}=E_{\text {corr }}^{\circ}+(R T / F) \ln \left(\mathrm{C}_{\mathrm{H}^{+}}\right) \\
& \frac{\partial E_{\text {corr }}}{\partial \ln \mathrm{C}_{\mathrm{H}^{+}}}=\frac{R T}{F} ; \quad \frac{\partial E_{\text {corr }}}{\partial \ln \mathrm{C}_{\mathrm{Cl}^{-}}}=0
\end{aligned}
$$

and

$$
\begin{aligned}
& i_{\text {corr }}=\left(k_{4}^{\prime} K_{1} K_{2} K_{3}\right)\left(\mathrm{C}_{\mathrm{H}^{+}}\right)^{1 / 2} \\
& \frac{\partial \ln i_{\text {corr }}}{\partial \ln \mathrm{C}_{\mathrm{H}^{*}}}=\frac{1}{2} ; \quad \frac{\partial \ln i_{\text {corr }}}{\partial \ln \mathrm{C}_{\mathrm{Cl}^{-}}}=0
\end{aligned}
$$

Table 3 compares the experimental results and the predictions of mechanism B. A closer agreement is now observed.

\section{Passivation Mechanism}

The experimental results obtained in the passivity region indicate that $\mathrm{ClO}_{4}^{-}$ions are required for the onset of passivity and the charge required for passivation largely exceeds that for the formation of a nonconducting film of the order of a monolayer thickness. Otherwise, stirring conditions have a definite influence on the passivating current, as revealed by the linear $i_{\mathrm{L}}$ vs $\omega^{1 / 2}$ plot (Fig. 6). These facts indicate that any solid state mechanism[16] to explain the passivity should be, in principle, discarded. However, a reasonable explanation can be achieved in terms of a precipitation dissolution mechanism.

Taking into account that passivation occurs when $\mathrm{ClO}_{4}^{-}$ion concentration exceeds largely the concentration of other anions, the scheme of reaction, which complements the mechanism of active dissolu-

\begin{tabular}{|c|c|c|c|}
\hline & $\begin{array}{c}\text { Mechanism } \\
\text { A }\end{array}$ & $\underset{B}{\text { Mechanism }}$ & $\begin{array}{l}\text { Experi- } \\
\text { mental } \\
\left(25^{\circ} \mathrm{C}\right)\end{array}$ \\
\hline$\left(\frac{\partial E}{\partial}\right)$ & $2 \cdot 3(4 R T)$ & $2 \cdot 3(4 R T)$ & $0.08-0.09 \mathrm{~V}$ \\
\hline$\left(\overline{\partial \log i_{\mathrm{p}}}\right)_{c_{\mathrm{i}}}$ & 3 & $3 F$ & $1000-009 \mathrm{~V}$ \\
\hline$(\partial E)$ & $2 \cdot 3(2 R T)$ & $2: 3(2 R T)$ & \\
\hline$\left(\overline{\partial \log i_{c}}\right)_{C_{l}}$ & $F$ & $F$ & $0.12-0.15 \mathrm{~V}$ \\
\hline$\left(\frac{\partial \log i_{u}}{\partial \log C_{\mathrm{I}^{+}}}\right)_{t C_{C \rightarrow \mathrm{H}^{+}}}$ & $\frac{1}{2}$ & 0 & $0-0.5$ \\
\hline$\left(\frac{\partial \log i_{\mathrm{a}}}{\partial \log C_{C_{1}}}\right)_{E, C_{1 \mp 0}}$ & $\frac{1}{7}$ & 0 & 0 \\
\hline$\left(\frac{\partial \log i_{\text {eorr }}}{\partial \log C_{\mathbf{H}^{+}}}\right)_{C_{i^{\prime}+\mathbf{H}^{+}}}$ & $\frac{3}{4}$ & $\frac{1}{2}$ & 0.5 \\
\hline$\left(\frac{\partial \log i_{\text {corr }}}{\partial \log C_{\mathrm{Cl}^{-}}}\right)_{C_{i} \neq \mathrm{Cl}}$ & $\frac{1}{4}$ & 0 & 0 \\
\hline$\left(\frac{\partial E_{\text {curr }}}{\partial \log C_{\mathrm{H}^{+}}^{-}}\right)_{C_{C_{*} \mathrm{H}^{+}}}$ & $\frac{2.3(R T)}{2 F}$ & $\frac{2 \cdot 3(R T)}{F}$ & $0.06 \mathrm{~V}$ \\
\hline$\left(\frac{\partial E_{\mathrm{cnrr}}}{\partial \log C_{\mathrm{Cl}^{-}}}\right)_{\mathrm{i}_{\mathrm{i} \neq \mathrm{c}^{-}}}$ & $-\frac{2 \cdot 3(R T)}{2 F}$ & 0 & 0 \\
\hline
\end{tabular}
tion, can be put forward as follows:
Table 3. Comparison of theoretical and experimental kinetic parameters

$C$ is the concentration of the passivating compound, $D$ its diffusion coefficient and $x$ is a distance normal to the electrode surface. Equation (24) is solved with the following initial and boundary conditions:

$$
\left.\begin{array}{l}
C(0, t)=C^{*} \\
C(\infty, t)=0 \\
C(x, 0)=0 \\
\frac{i_{a}}{2 F}=-\mathrm{D}\left(\frac{\partial C}{\partial x}\right)_{x=0}=F(t)
\end{array}\right\}
$$

where $F(t)$ depends on the experimental technique employed. The solution of equation (24) with conditions (25), under galvanostatic conditions $(F(t)=$

$$
\begin{aligned}
\mathrm{Ni}+6 \mathrm{DMSO} & =\mathrm{Ni}(\mathrm{DMSO})_{6}^{2+}+2 e \\
\mathrm{Ni}(\mathrm{DMSO})_{6}^{2+}+2 \mathrm{ClO}_{4}^{-} & =\mathrm{Ni}(\mathrm{DMSO})_{6}\left(\mathrm{ClO}_{4}\right)_{2} \\
\mathrm{Ni}(\mathrm{DMSO})_{6}\left(\mathrm{ClO}_{4}\right)_{2}+4 \mathrm{HCl} & =\mathrm{NiCl}_{4}^{2-}+4 \mathrm{H}^{+}+6 \mathrm{DMSO}+2 \mathrm{ClO}_{4}^{-}
\end{aligned}
$$

The anodic metal dissolution (B-1) to (B-5) is an irreversible process, as already discussed. The compensation of $\mathrm{Ni}$ (II) charges at the interface occurs more likely through the participation of $\mathrm{ClO}_{4}^{-}$ions. When the rate of $\mathrm{Ni}$ (II) formation becomes faster than the diffusion of $\mathrm{Ni}(\mathrm{DMSO})_{6}\left(\mathrm{ClO}_{4}\right)_{2}$ out of the interface, its local concentration attains a value larger than a critical value $\mathrm{C}^{*}$ related to the solubility product of the salt then it precipitates in the electrode vicinity causing a decrease of the anodic dissolution current.

The precipitate is in equilibrium with the various $\mathrm{Ni}(\mathrm{II})$ complexes in solution and its dissolution (step B-5a) is determined by Fick's law:

$$
\frac{\partial C}{\partial t}=D \frac{\partial^{2} C}{\partial x^{2}}
$$

const) yields for $C^{*}$ the following expression[17]:

$$
C^{*}=\frac{i_{a}}{2 F(\pi D)^{1 / 2}} \tau^{1 / 2}
$$

where $\tau$ is the time required to attain passivation $(C=$ $\left.C^{*}\right)$. For the galvanostatic runs equation (26) predicts $i \tau^{1 / 2}=$ const. Assuming $D=10^{-5} \mathrm{~cm}^{2} / \mathrm{s}$, the estimated value of $C^{*}$ results of the order of $10^{-4}$ mole/ $\mathrm{cm}^{3}$, which coincides with the value obtained from $\mathrm{Ni(II)} \mathrm{solubility} \mathrm{estimations} \mathrm{in} 1 \mathrm{M} \mathrm{KClO}_{4}$. That figure corresponds to an electrolyte of a relatively high solubility.

Other reaction pathways involving competitive steps, such as the one discussed by various authors $[18,19]$ for nickel passivation in aqueous solutions, 
predict a different $i \tau^{1 / 2}$ us $i$ dependence that the one previously reported in this paper.

The shape of the potentiostatic $I / t$ profile approaches the prediction of a simple precipitationdissolution mechanism (Fig. 9) but the charge required increases as the rate of dissolution decreases. The postulated mechanism implies that a longer time should be required to reach the critical concentration when the rate of complex salt formation (B-5a) diminishes, becausc its prccipitation must occur within a thicker layer adjacent to the electrode. This effect has already been noticed with other passivation processes controlled by a precipitation-dissolution mechanism $[21,22]$.

The effect of stirring on the passivity current can also be accounted for with a precipitation and dissolution process based upon a nucleation mechanism[23]. Accordingly, provided the kinetic conditions imposed upon the reaction scheme are valid, the limiting current density obtained with the rde should depend on the square root of the rotation speed, as found experimentally (Fig. 6).

In conclusion, the results discussed in this paper indicate that the anodic nickel corrosion in $\mathrm{HCl}-\mathrm{DMSO}$ solutions is an electrochemical activated process which is accompanied by a passivation effect due to a dissolution-precipitation mechanism of a Ni(II) salt. The latter is clearly evidenced when $\mathrm{ClO}_{4}^{-}$ions are present in the solution at a relatively high concentration.

Acknowledgements-This work is part of the research programme of the Electrochemistry Division of Instituto de Investigaciones Fisicoquímicas Teóricas y Aplicadas (INIFTA), sponsored by the Universidad de La Plata, the Consejo Nacional de Investigaciones Cientificas y Técnicas and the Comisión de Investigaciones Cientificas de la Provincia de Buenos Aires. A. Delgado acknowledges the Consejo Nacional de Investigaciones Cientificas y Técricas the fellowship granted.

\section{REFERENCES}

1. D. Posadas, A. J. Arvia and J. J. Podestá, Electrochim. Acta 16, 1025 (1971).
2. D. Posadas, A. J. Arvia and J. J. Podestá, Electrochim. Acta 16, 1041 (1971).

3. O. Derosa, V. Macagno and M. C. Giordano, Comm. 1st. Latin-American Meeting of Electrochem. p. 27, La Plata (1972).

4. A. J. Arvia and D. Posadas, Electrochemistry of the Elements, (Edited by A. J. Bard), Vol. 3, Chap. 1. M. Dekker, New York (in press).

5. A.J. Arvia and J. J. Podestá, Corrosion Metálica, Chap. 1, Servicio Naval de Investigación y Desarrollo, Bucnos Aircs (1973).

6. R. C. V. Piatti, J. J. Podestá and A. J. Arvia, Electrochim. Acta 14, 541 (1969)

7. W. J. McTegart, The Electrolytic and Chemical Polishing of Metals, Pergamon Press, London (1956).

8. G. Paús, A. J. Calandra and A. J. Arvia, An. Asoc. quím. Argent. 192, 35 (1971).

9. A. Delgado, D. Posadas and A. J. AIvia, Electrochirs. Acta 18, 657 (1973).

10. M. M. Nicholson and I. Shain, Analyt. Chem. 36, 706 (1964).

11. F. Ovari and A. L. Rotinyan, Soviet Electrochem. 6, 516 (1970).

12. A. L. Rotinyan, V. Ya. Zel'des, E. Sh. Ioffe and E. S. Kozich, Zh. fiz. Khim. 28, 74 (1954).

13. D. W. Meek, D. K. Straub and R. S. Drago, J. am. Chem. Soc. 82, 6013 (1960).

14. I. A. Bolzan and A. J. Arvia, Electrochim. Acta 15, 39 (1970).

15. A. J. Arvia and J. J. Podestá, Corros. Sci. 8, 203 (1968).

16. R. D. Armstrong, J. A. Harrison and H. R. Thirsk, Corros. Sci. 10, 687 (1970).

17. S. Asakura and K. Nobe, $J$.electrochem. Soc. 118, 19 (1971).

18. A. K. N. Reddy, M. A. V. Devanathan and J. O'M. Bockris, J. electroanal. Chem. 6, 61 (1963).

19. R. D. Armstrong and J. A. Harrison, J. electroanal. Chem. 36, 79 (1972).

20. U. R. Evans, Metallic Corrosion Passitity and Pratection, p. 42, Arnold, London (1937).

21. R. S Cooper, J. electrochem. Soc. 103, 307 (1956).

22. A. J. Calandra, N. R. de Tacconi, R. Pereiro and A. J. Arvia, Electrochim. Acta 19, 901-906.

23. R. D. Armstrong, Corros. Sci. 11, 693 (1971). 